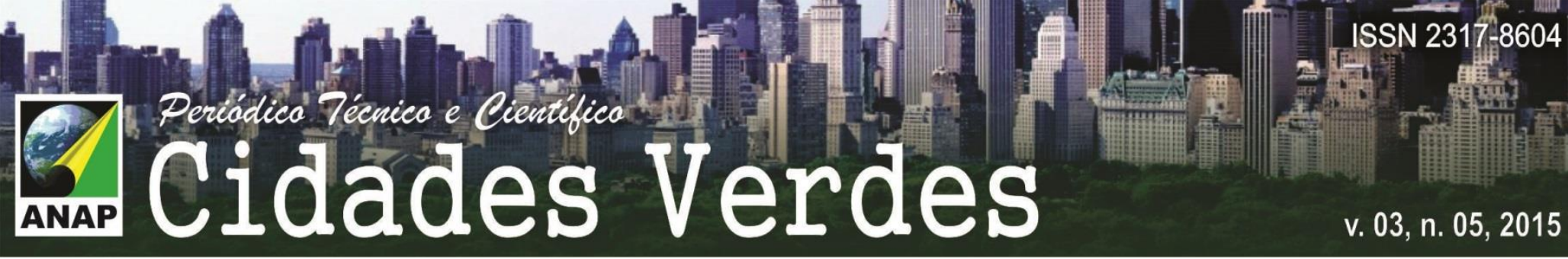

\title{
INTERVENÇÃO URBANA - PROJETO DE REVITALIZAÇÃO DAS ÁREAS VERDES DE UM DOS AFLUENTES DO RIO CAMANDUCAIA, JAGUARIÚNA-SP
}

\author{
Paula Rezende Montano ${ }^{1}$
}

\author{
Eduardo Vinícius Rocha Pires ${ }^{2}$
}

\section{RESUMO}

O presente projeto foi a idealização para a requalificação da área próxima à um dos afluentes do Rio Camanducaia, que atravessa a área urbana, que se encontra degradada devido à falta de infraestrutura e planejamento urbano. Este projeto, então, idealiza trazer à população da região do afluente uma área agradável e de uso comum, sendo ponto de visitação tanto para a população de Jaguariúna-SP, quanto à toda a população da região metropolitana de Campinas-SP. Para isso, foram feitos mapas e cartas, para análises, planejamentos e futuras tomadas de decisões para intervenções urbanas no que tange à revitalizações de áreas verdes.

PALAVRAS-CHAVE: Intervenção Urbana. Revitalização. Áreas Verdes.

\section{URBANA INTERVENTION REVITALIZATION - PROJECT OF A GREEN AREAS OF CAMANDUCAIA RIVER TRIBUTARIES JAGUARIÚNA-SP}

\begin{abstract}
This project was the idealization for the redevelopment of the area near a tributary of the Rio Camanducaia, which runs through the urban area, which is degraded due to lack of infrastructure and urban planning. This project, then, envisions bringing the population of affluent region a nice area and in common use, and visiting point for both the population of Jaguariúna-SP, as the entire population of the metropolitan region of Campinas-SP. For this, they made maps and charts for analysis, planning and decision-making for future urban interventions regarding the revitalization of green areas.
\end{abstract}

KEYWORDS: Urban Intervention. Revitalization. Green areas.

\footnotetext{
${ }^{1}$ Acadêmica de Arquitetura e Urbanismo, Universidade Paulista. paula.montano@outlook.com

${ }^{2}$ Mestrando em Geografia, Professor Substituto do Curso de Geografia - UFMT - Cuiabá. drocha.geo@gmail.com
} 


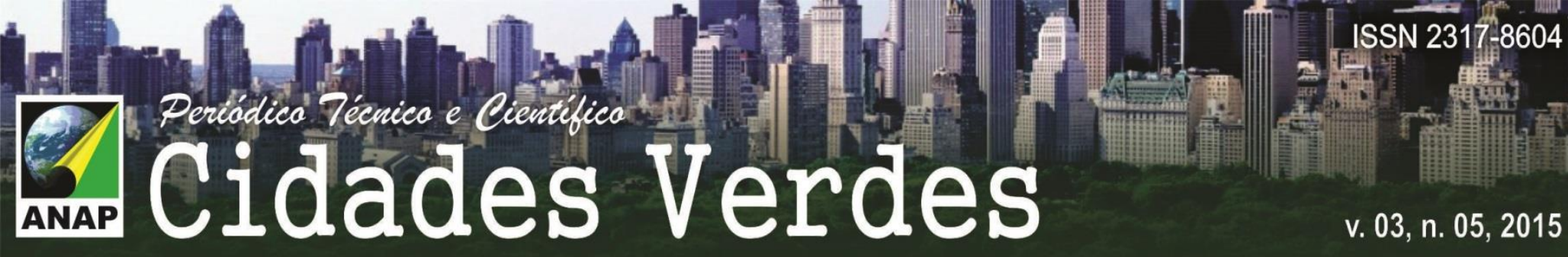

\title{
URBANA REACTIVACIÓN DE INTERVENCIÓN DEL PROYECTO DE A ZONAS VERDES DE CAMANDUCAIA RÍO TRIBUTARIOS JAGUARIUNA-SP
}

\begin{abstract}
RESUMEN
Este proyecto fue la idealización de la reurbanización de la zona cerca de un afluente del Río Camanducaia, que atraviesa la zona urbana, que se degrada debido a la falta de infraestructura y la planificación urbana. Este proyecto, a continuación, imagina lo que la población de la región opulenta una zona agradable y de uso común, y el punto de visitar, tanto para la población de Jaguariúna-SP, ya que toda la población de la región metropolitana de Campinas-SP. Para ello, se realizan mapas y gráficos para el análisis, la planificación y la toma de decisiones para intervenciones urbanas futuras relativas a la revitalización de las zonas verdes.
\end{abstract}

PALABRAS CLAVE: Intervención urbana. Revitalización. Areas verdes.

\section{INTRODUÇÃO}

O crescimento desordenado das cidades brasileiras e as consequências geradas pela falta de planejamento urbano despertaram a atenção de planejadores e da população no sentido de se perceber a vegetação como componente necessário ao espaço urbano. Dessa forma, mais expressivamente, a arborização passou a ser vista nas cidades como importante elemento natural atuando como reestruturador do espaço urbano, pois as áreas bastantes arborizadas apresentam uma aproximação maior das condições ambientais normais em relação ao meio urbano que apresenta, entre outros, temperaturas mais elevadas, particularmente, nas áreas de elevados índices de construção e desprovidas de cobertura vegetal (CARVALHO, 1982, p. 63).

A necessidade de uma distribuição mais igualitária de áreas verdes na cidade é destacada por vários autores, pois a localização destas, na maioria das vezes, está associada à especulação imobiliária. Assim, os espaços destinados ao lazer, quer sejam parques e praças públicas, quando bem equipados, tornam as áreas em seu entorno mais valorizadas e, consequentemente, procuradas pela garantia de 


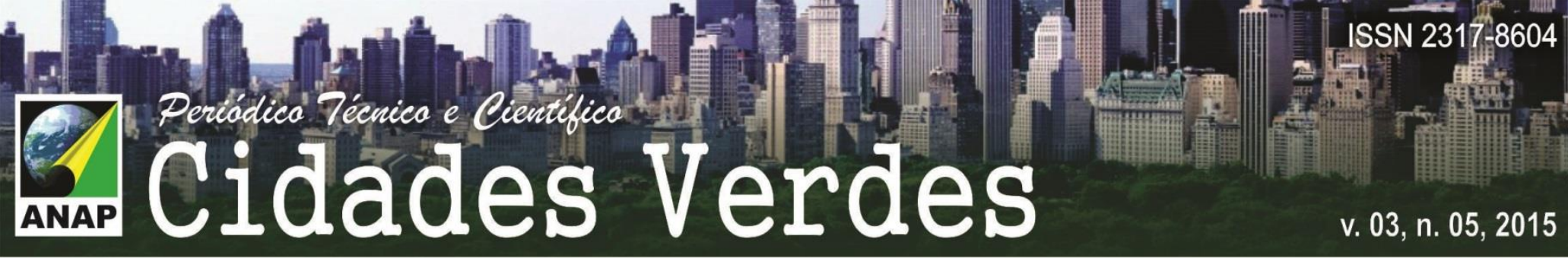

Figura 1: Carta de Leitura e Suporte Físico da Área do Projeto

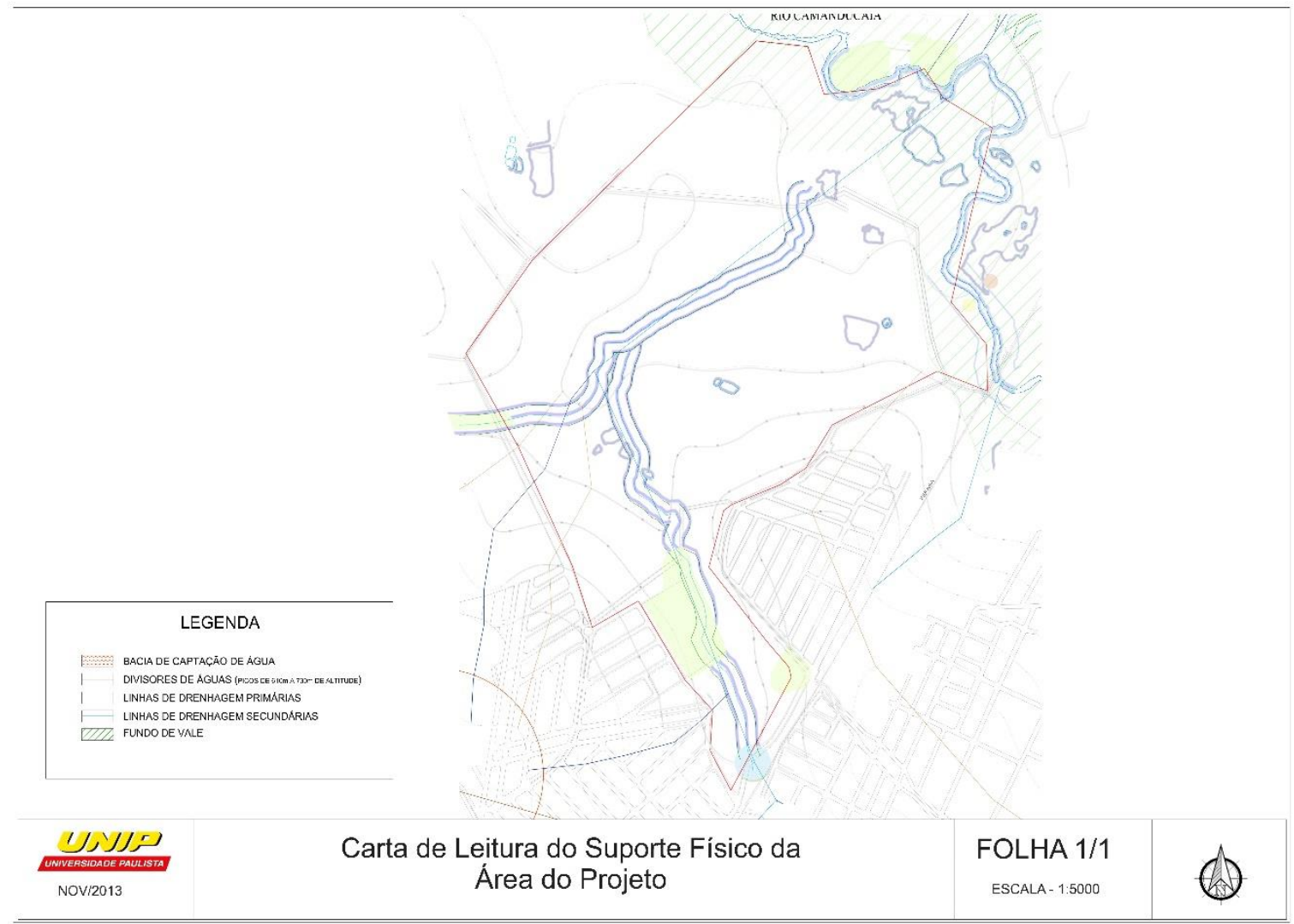

Posteriormente foi escolhido uma das áreas mais carente de revitalização, devido à sua distância do centro da cidade, característico por ser um bairro periférico, tendo sua infraestrutura carecida de "Direitos à Cidade".

Dessa forma, sobretudo em razão da especulação imobiliária, produziu-se uma situação aparentemente paradoxal: enquanto um enorme contingente populacional se aglomerava na periferia da cidade vivendo em condições precárias ao extremo, inúmeros terrenos e imóveis vazios e/ou ociosos conformavam a paisagem urbana - um grande número deles, inclusive, na área central. Com isso, permanecem vários espaços vazios nessa área - os chamados vazios urbanos - ao passo que a malha da cidade se espraia de forma contínua e horizontal. ( MARICATO, 1994)

Para um estudo mais aprofundado da realidade da cidade, foram feitas visitas regulares e registros fotográficos de cada ponto urbano. 


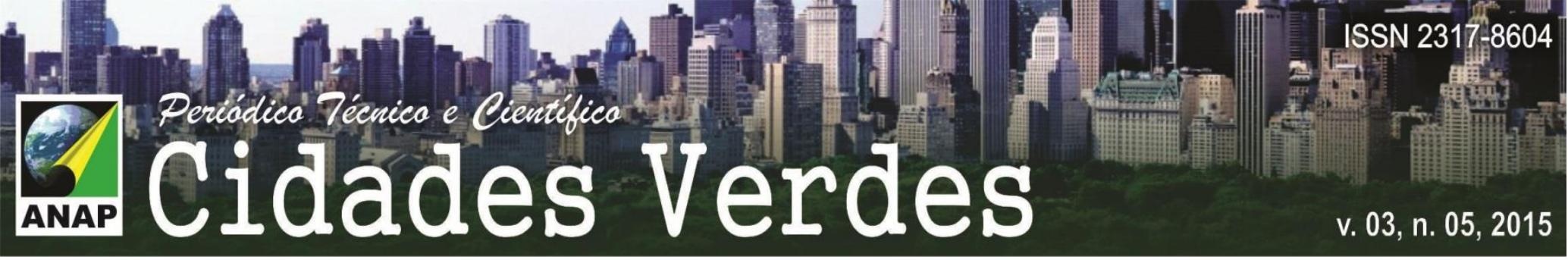

Para a realização do mapeamento em formato de plantas e cartas, foram utilizados os softwares AutoCAD®, Adobe Photoshop® e CorelDRAW ${ }_{\circledast}$.

\section{RESULTADOS}

Os resultados obtidos à partir do mapeamento preliminar e das visitas técnicas serviram para gerar algumas cartas que nos dão bases para uma futura revitalização da área e suas respectivas tomadas de decisão.

Figura 1: Uso e ocupação da área de estudo.

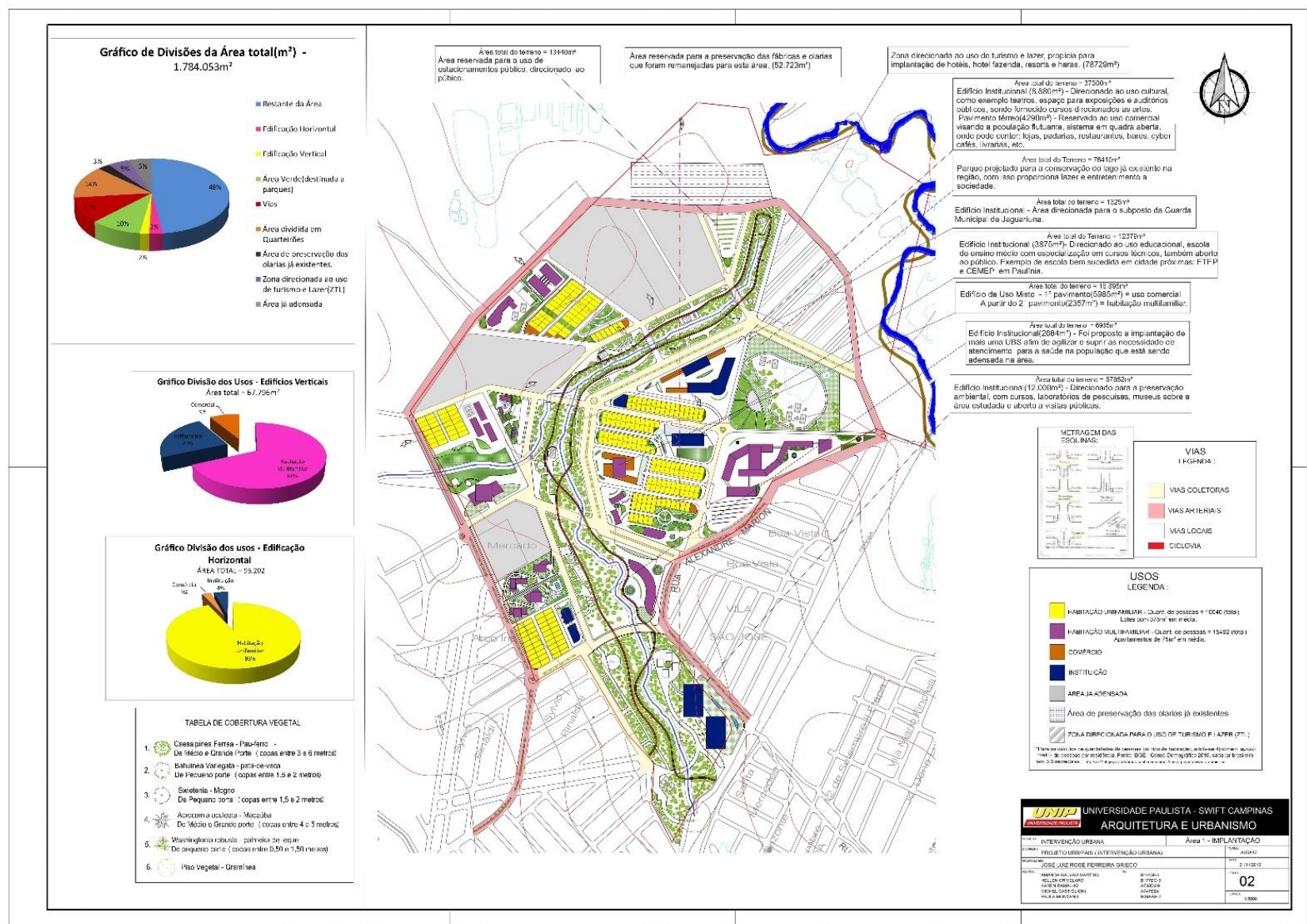

Fonte: Montano, 2013 Org.: Montano, 2013 


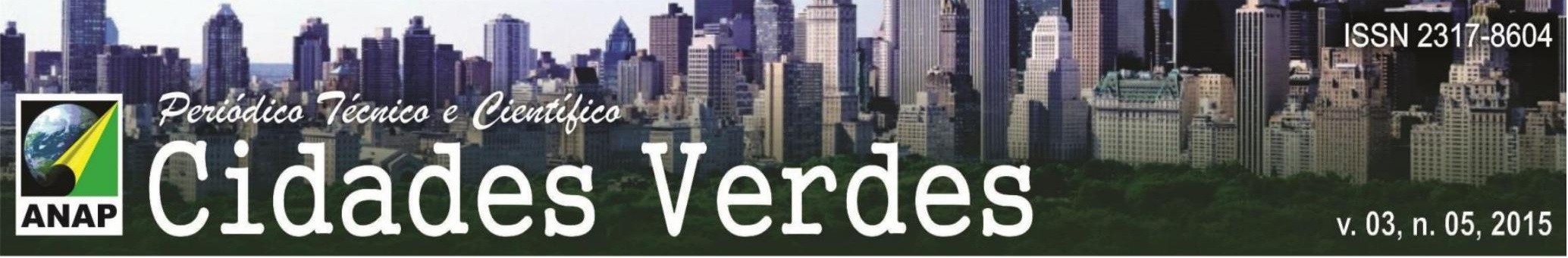

Gráfico 1: Divisões da Área Total

Gráfico de Divisões da Área total $\left(\mathrm{m}^{2}\right)$ -

$1.784 .053 \mathrm{~m}^{2}$

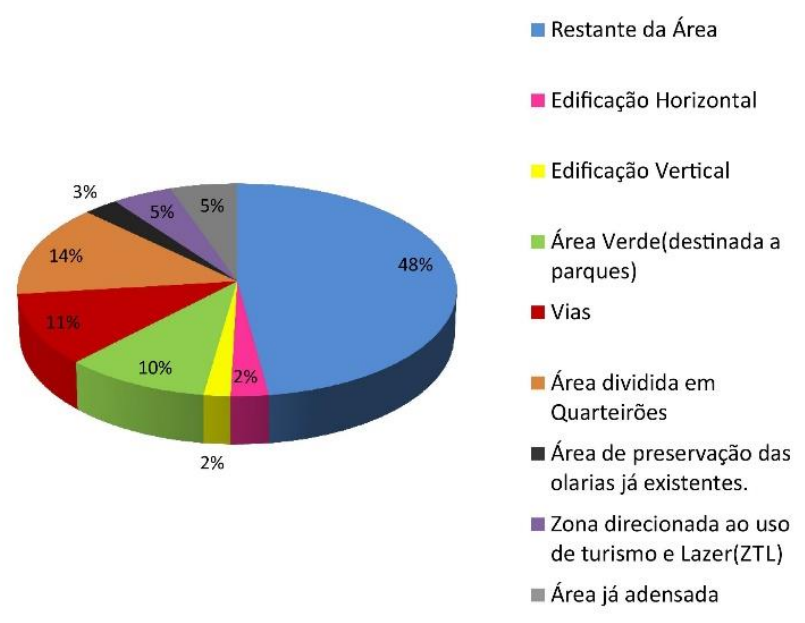

Fonte: Montano, 2013

Gráfico 2: Divisão de Usos- Edifícios Verticais

Gráfico Divisão dos Usos - Edifícios Verticais

Área total $=67.796 \mathrm{~m}^{2}$

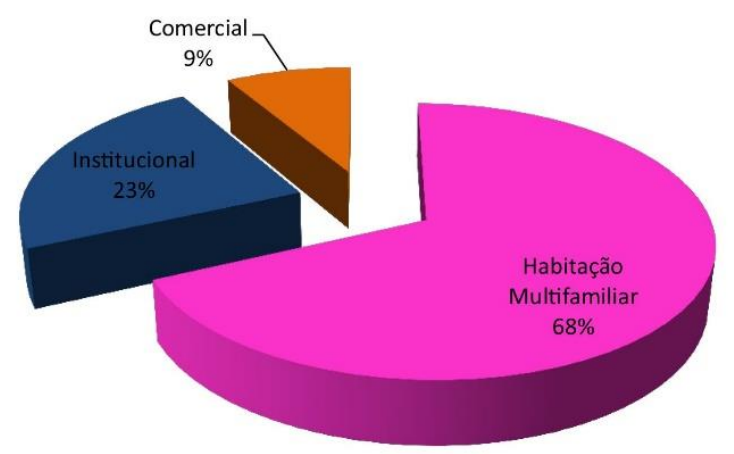

Fonte: Montano, 2013 


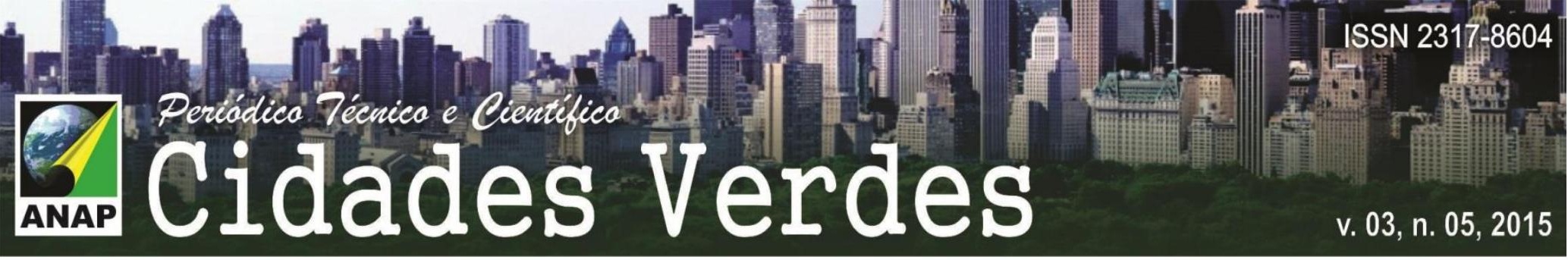

\section{Gráfico 3: Gráfico dos Usos - Edificação Horizontal}

\section{Gráfico Divisão dos usos - Edificação}

Horizontal

ÁREA TOTAL $=95.202$

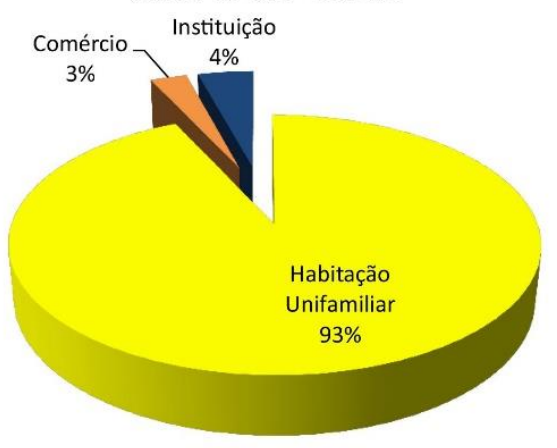

Fonte: Montano, 2013

Sabendo disso, foi feito um mapa de localização das manchas de vegetação, dos parques e das unidades de conservação.

Figura 2: Manchas de Vegetação, Localização dos parques e preservação das UCs

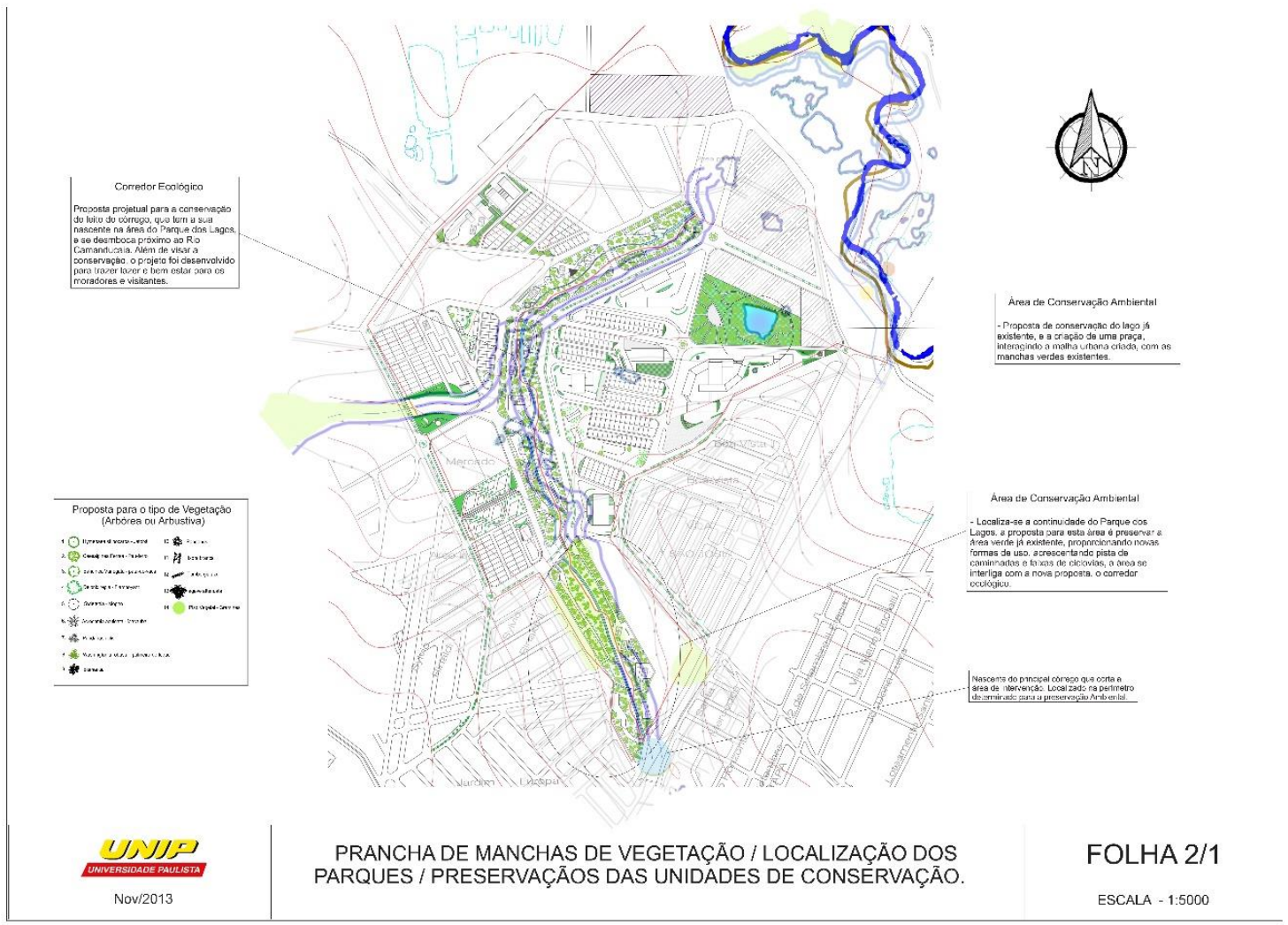

Fonte: Montano, 2013 


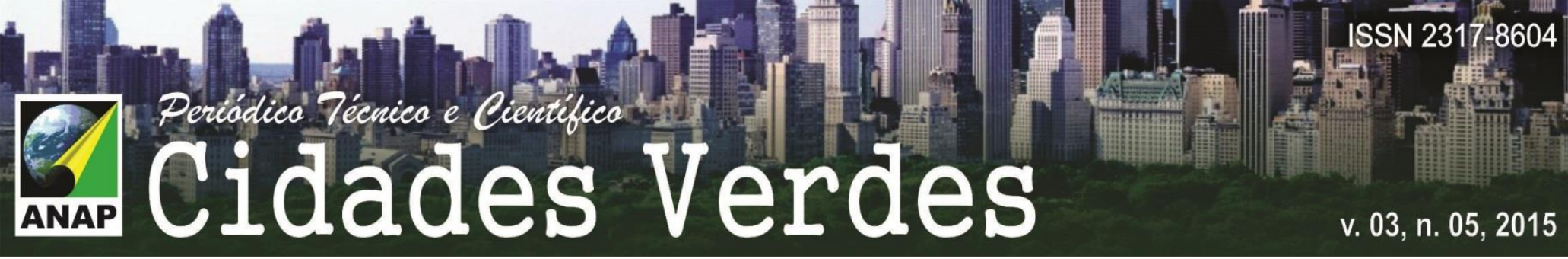

Figura 3: Plano de Massa - Divisão de áreas a partir do uso

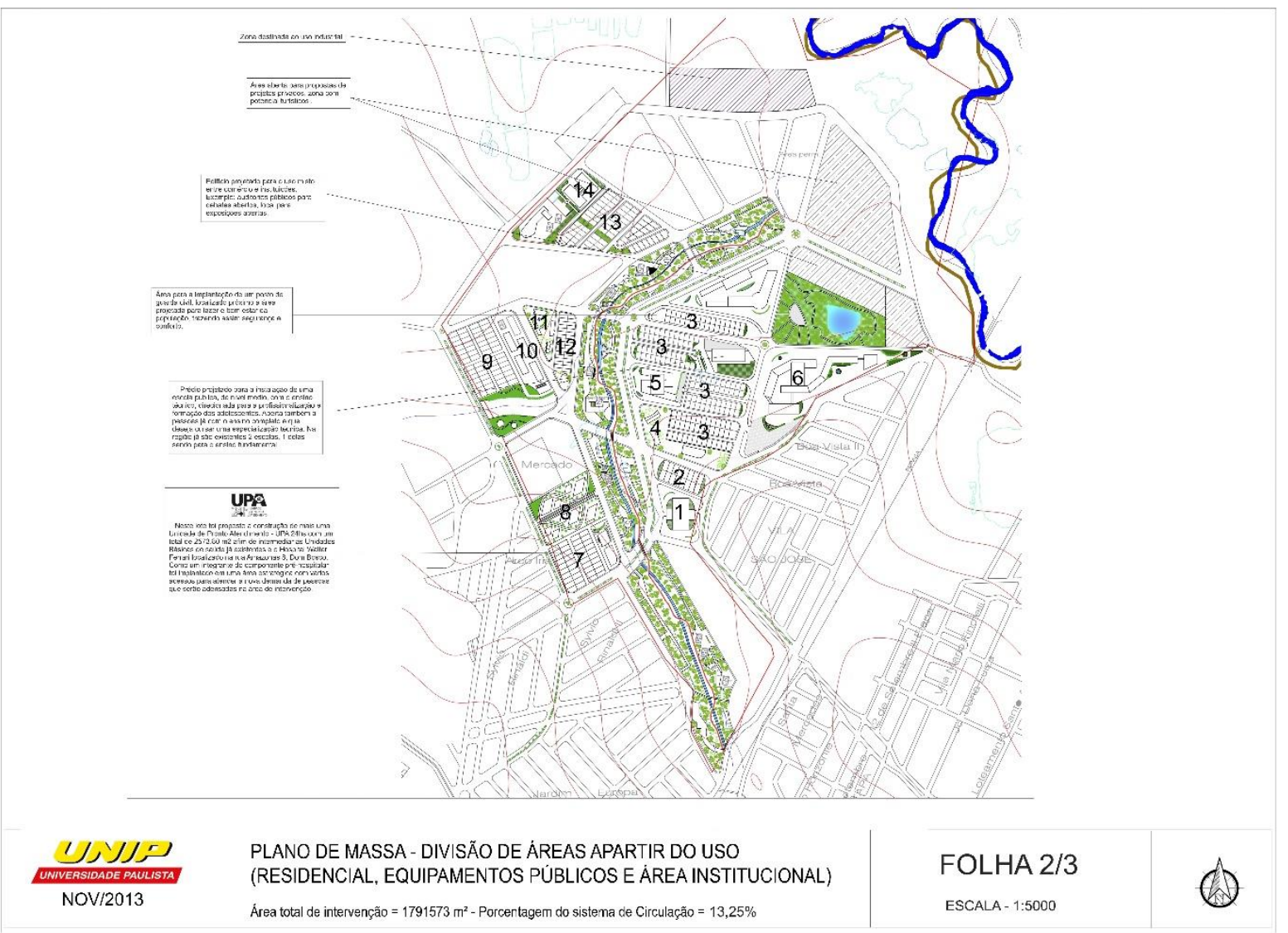

Fonte: Montano, 2013

A partir do levantamento de campo, foi proposto um plano de uso e ocupação dessa área próxima ao afluente do Rio Camanducaia (o qual possui APP urbana), para o conforto e todos os outros fatores que fazem com que o Índice de Desenvolvimento Humano e o Direito à Cidade esteja à disposição da população dessa região. 
